\title{
Supplemental Material: Shear-induced ordering of nano-pores and instabilities in concentrated surfactant mesh phases
}

\author{
Pradip K. Bera吃, Vikram Rathee呢, Rema Krishnaswamy听 and A.K. Sood吨 \\ ${ }^{1}$ Department of Physics, Indian Institute of Science, Bangalore 560012, India
}

a These authors contributed equally to this work.

${ }^{\mathrm{b}}$ Present address: Okinawa Institute of Science and Technology Graduate University, Okinawa, Japan

${ }^{c}$ Present address: School of Liberal Studies, Azim Premji University, Bangalore, 560100, India

* asood@iisc.ac.in 


\section{A. Equilibrium phase diagrams of CTAB-SHN-water and CPC-SHN-water}

Equilibrium phase diagram of the CTAB-SHN-water system $(\alpha=1)$ is shown in Fig. S1(a). Figure S1(b) shows the equilibrium phase diagram of the CPC-SHN-water system $(\alpha=0.5)$. At $30^{\circ} \mathrm{C}$, the $\mathrm{L}_{\alpha}^{D}$ phase is observed for $0.25<\phi<0.5$ in CTAB-SHN-water system, and for $0.43<\phi<0.57$ in CPC-SHN-water system. At $30^{\circ} \mathrm{C}$, the $\mathrm{R} \overline{3} \mathrm{~m}$ phase is observed for $0.5<\phi<0.7$ in CTAB-SHN-water system, and for $0.57<\phi<0.75$ in CPC-SHN-water system.
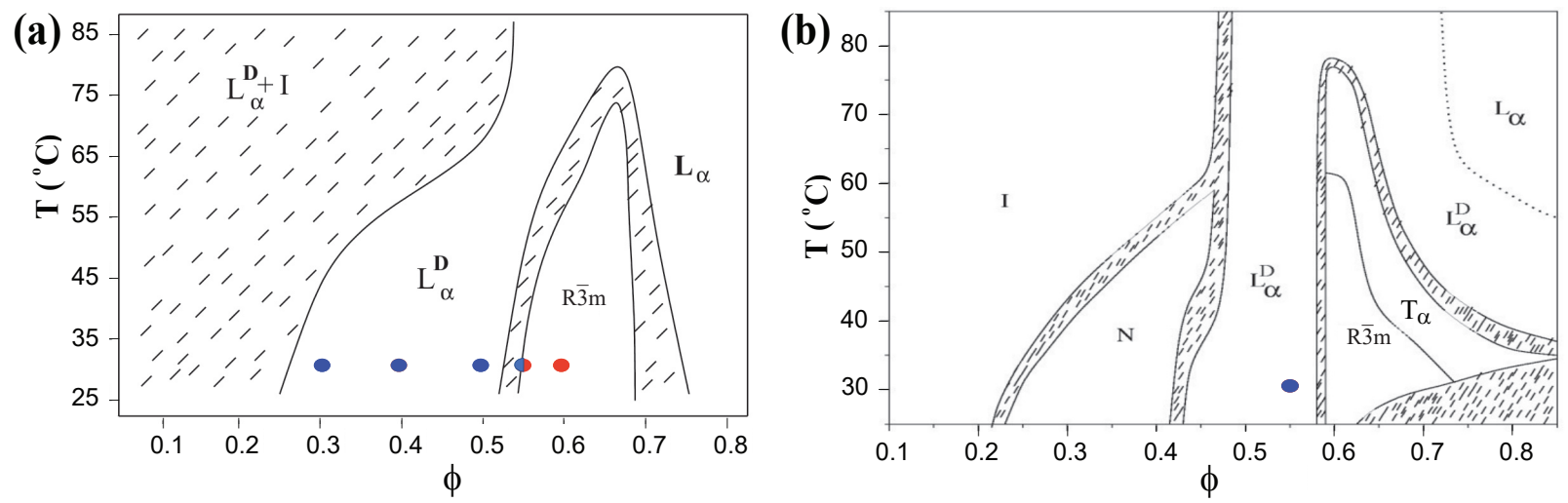

FIG. S1. (a) Equilibrium phase diagram showing total weight fraction of surfactant + SHN $(\phi)$ vs temperature $(\mathrm{T})$ of CTAB-SHN-water at equimolar ratio $(\alpha=1)$. (b) Similar phase diagram of CPC-SHN-water at molar ratio $\alpha=0.5 . \mathrm{L}_{\alpha}^{D}, \mathrm{I}, \mathrm{R} \overline{3} \mathrm{~m}, \mathrm{~L}_{\alpha}, \mathrm{N}, \mathrm{T}_{\alpha}$ denote the random mesh, isotropic, rhombohedral mesh, lamellar, nematic, tetragonal mesh phases, respectively. The blue and the red dot marks show the compositions studied by us. The phase diagrams are adopted from [1], and [2], respectively.

\section{B. Estimation of a single pore's volume of $\mathbf{L}_{\alpha}^{D}$ and $\mathbf{R} \overline{3} \mathbf{m}$ using the right rhombic} prism model [Fig. S2]

Using the surfactant weight fraction $\phi$ as defined in the main text, assuming the same density for the surfactant and SHN i.e $\rho_{s}$ in the bilayers, it can be shown [Fig. S2] that if $\mathrm{V}_{w}$ is the total volume occupied by water and $\mathrm{V}_{s}$ is the total volume occupied by surfactant+SHN 
then we have,

$$
\begin{aligned}
& \Rightarrow \frac{V_{w}}{V_{s}}=\frac{f_{\rho}}{\psi} ; \quad \text { where } f_{\rho}=\frac{\rho_{s}}{\rho_{w}} \text { and } \psi=\frac{W_{\text {surfactant }+S H N}}{W_{\text {water }}}=\frac{\phi}{1-\phi} \\
& \Rightarrow \frac{(\sqrt{3} / 2) d_{d}^{2}\left(d_{l}-2 r\right)+\pi R^{2} 2 r}{\left((\sqrt{3} / 2) d_{d}^{2}-\pi R^{2}\right) 2 r}=\frac{f_{\rho}}{\psi} \\
& \Rightarrow \pi R^{2} 2 r\left(f_{\rho}+\psi\right)=(\sqrt{3} / 2) d_{d}^{2}\left(2 r f_{\rho}-\left(d_{l}-2 r\right) \psi\right) \\
& \Rightarrow \text { pore volume } \sim \pi R^{2} 2 r=\frac{(\sqrt{3} / 2) d_{d}^{2}\left(2 r f_{\rho}-\left(d_{l}-2 r\right) \psi\right)}{\left(f_{\rho}+\psi\right)}
\end{aligned}
$$

Table $\mathrm{S} 1$ shows the estimated pore volume of $\mathrm{L}_{\alpha}^{D}$ and $\mathrm{R} \overline{3} \mathrm{~m}$ for different surfactant concentration, using the measured in-plane pore correlation length $\left(d_{d}\right)$ and the bilayer periodicity $\left(d_{l}\right)$ of $\mathrm{L}_{\alpha}^{D}$ phase or using the measured lattice parameters of $\mathrm{R} \overline{3} \mathrm{~m}$ phase at equilibrium.

TABLE S1. Estimation of volume of the in-plane water filled pore for different $\phi$. Taken value of $\mathrm{r}=2.1 \mathrm{~nm}$ (from literature) and $\mathrm{f}_{\rho}=1.03$ (measured).

\begin{tabular}{cccccc}
\hline \hline system & $\phi$ & the phase $\mathrm{d}_{d}$ or a $(\mathrm{nm}) \mathrm{d}_{l}$ or c/3 $(\mathrm{nm})$ pore volume $\left(\mathrm{nm}^{3}\right)$ \\
\hline CTAB-SHN-Water & 0.40 & $\mathrm{~L}_{\alpha}^{D}$ & 7.68 & 7.05 & 72.60 \\
& 0.50 & $\mathrm{~L}_{\alpha}^{D}$ & 7.67 & 5.49 & 76.19 \\
& 0.53 & $\mathrm{R} \overline{3} \mathrm{~m}$ & 8.95 & 5.44 & 94.06 \\
& 0.60 & $\mathrm{R} \overline{3} \mathrm{~m}$ & 8.30 & 4.70 & 84.32 \\
\hline CPCl-SHN-Water & 0.55 & $\mathrm{~L}_{\alpha}^{D}$ & 6.50 & 5.13 & 51.90 \\
\hline \hline
\end{tabular}




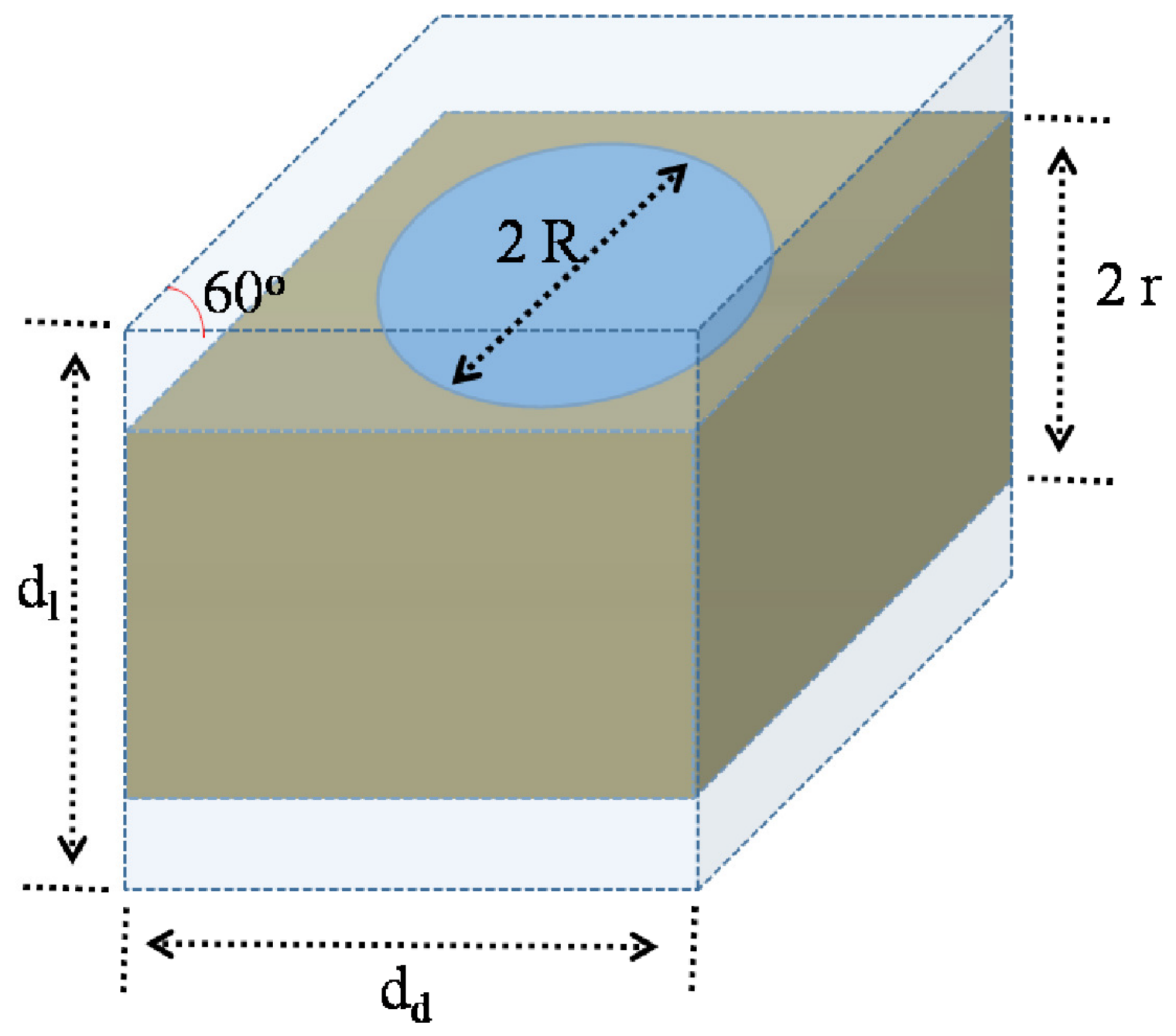

FIG. S2. Right rhombic prism of sides $\mathrm{d}_{d}, \mathrm{~d}_{d}$ with angle $60^{\circ}$ and height $\mathrm{d}_{l}$. Surfactant layer of thickness $2 \mathrm{r}$ has a cylinder of diameter $2 \mathrm{R}$ at the centre filled with water. Top and bottom space out side the surfactant is filled with water. 


\section{SAXS diffractograms showing $\mathbf{L}_{\alpha}^{D}$ to $\mathbf{R} \overline{3} \mathbf{m}$ transition, and the reversibility}

For CTAB-SHN-water system $(\phi=0.5, \alpha=1)$ during the random mesh phase $\left(\mathrm{L}_{\alpha}^{D}\right)$ to rhombohedral mesh phase $(\mathrm{R} \overline{3} \mathrm{~m})$ transition, the SAXS diffractograms are calculated by azimuthal integration of intensity with respect to the SAXS pattern centre, and then averagred over no of pixels, considered during azimuthal integration [Fig. S3]. After stopping the shearing experiment the SAXS pattern was recorded for $250 \mathrm{~s}$ in order to check the reversibility of the transition. Figure S4 shows the normalized intensities of [101], and [110] Bragg peaks (normalized with respect to intensity at the time of stopping the shear) during the relaxation of the shear induced $\mathrm{R} \overline{3} \mathrm{~m}$ phase. 


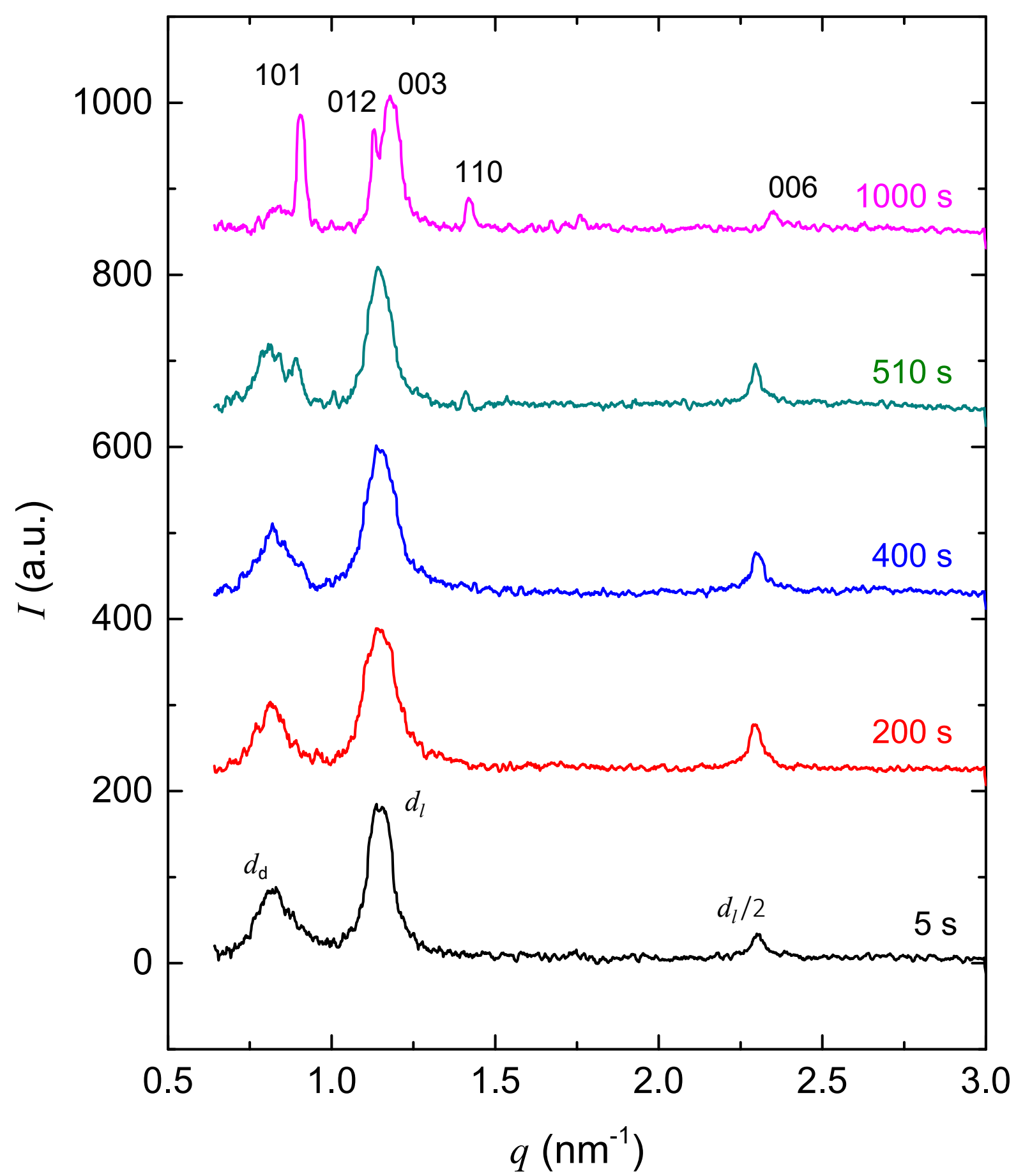

FIG. S3. Temporal evolution of the SAXS diffractogram during the random mesh phase $\left(\mathrm{L}_{\alpha}^{D}\right)$ to rhombohedral mesh phase $(\mathrm{R} \overline{3} \mathrm{~m})$ transition at a shear rate $=50 \mathrm{~s}^{-1}$ using PP geometry, for CTAB-SHN-water system $(\phi=0.5, \alpha=1)$. Initial Bragg peaks corresponding to the lamellar d-spacing $\left(d_{l}\right)$, the diffuse scattering peak due to the in-plane correlation of the nano-pores $\left(d_{d}\right)$, and a few Bragg peaks of the shear-induced $\mathrm{R} \overline{3} \mathrm{~m}$ are indicated. 


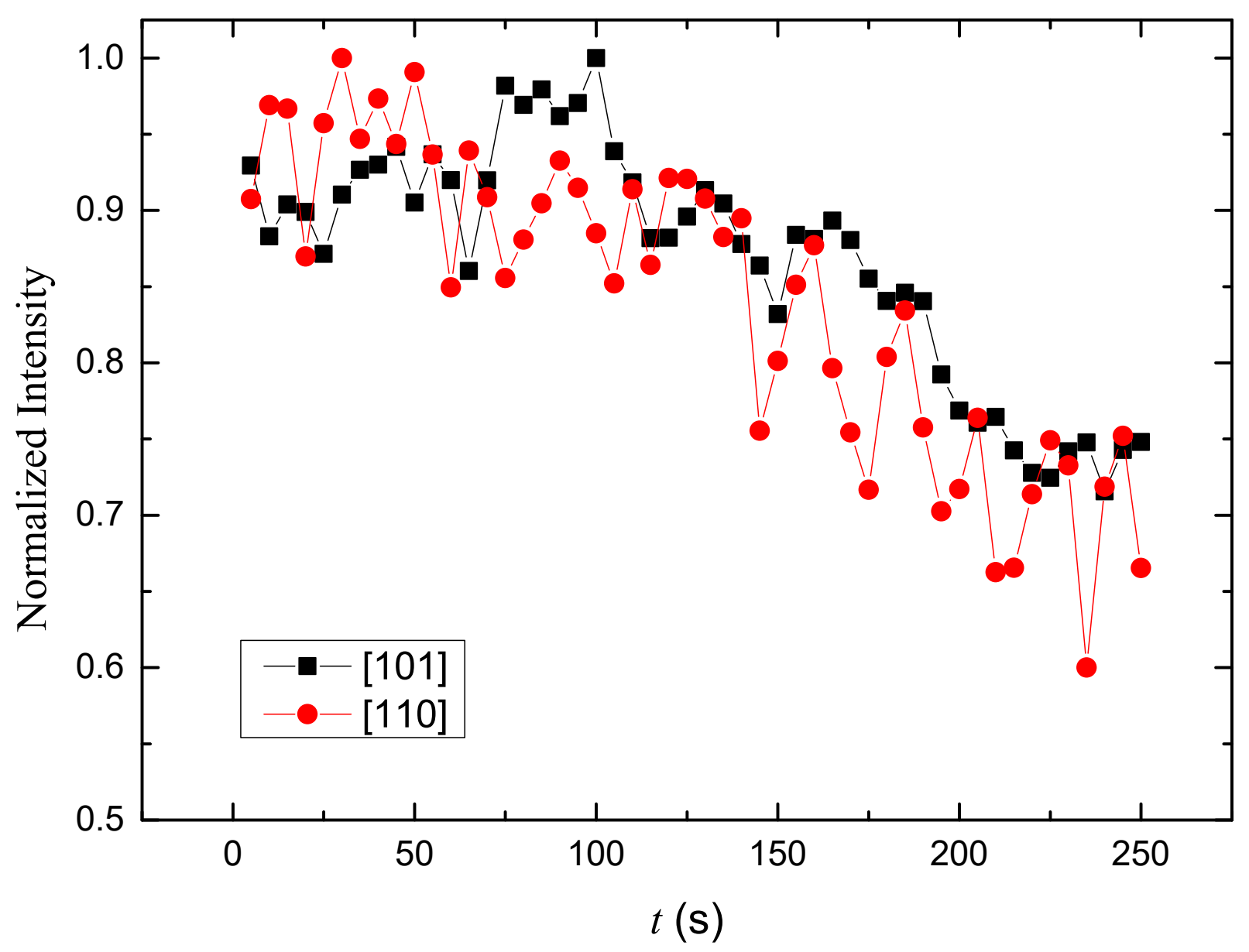

FIG. S4. Decrease of the normalized intensities of [101], and [110] Bragg peaks (normalized with respect to intensity at the time of stopping the shear) during the relaxation of the shear induced $\mathrm{R} \overline{3} \mathrm{~m}$ phase after stopping the shear using PP geometry, for CTAB-SHN-water $(\phi=0.5, \alpha=1)$. 


\section{Shear-induced $\mathbf{L}_{\alpha}^{D}$ phase to $\mathbf{R} \overline{3} \mathbf{m}$ non-equilibrium phase transition (NEPT) in CPC-SHN-water system, and the reversibility}

With PP geometry, shear-induced $\mathrm{L}_{\alpha}^{D}$ phase to $\mathrm{R} \overline{3} \mathrm{~m}$ non-equilibrium phase transition (NEPT) in the CPC-SHN-water system $(\alpha=0.5, \phi=0.55)$ is observed during the stress relaxation at $\dot{\gamma}=50 \mathrm{~s}^{-1}$ [Fig. S5(a)]. In equilibrium, as shown in Fig. S5(b), the X-ray diffraction pattern reveals an unoriented lamellar with $d$-spacing of $5.13 \mathrm{~nm}$, coexisting with the diffuse peak from nano-pores with $6.50 \mathrm{~nm}$ liquid-like average correlation length. A nearly a-oriented diffraction pattern is obtained at $t \sim 10 \mathrm{~s}$, with the average orientation of lamellar peaks along $\mathbf{q}_{\perp}$ [Fig. S5(c)]. The azimuthal spread of the lamellar peak decreases upon further shearing and at $t \sim 20 \mathrm{~s}$ [Fig. S5(d)], a sharp peak comes up after the diffuse peak indicating 3D ordering of nano-pores getting established under shear similar to the observation in the case of CTAB-SHN-water system (discussed in the main text). After $t=30 \mathrm{~s}$, other higher order peaks start appearing [Fig. S5(e)]. All the sharp reflections obtained at $t \sim 40 \mathrm{~s}$ [Fig. S5(f)], can be indexed to two R $\overline{3} \mathrm{~m}$ phases with lattice parameters $a 1=8.39 \mathrm{~nm} ; c 1=14.79 \mathrm{~nm} ; a 2=8.27 \mathrm{~nm} ; c 2=14.28 \mathrm{~nm}$ [Table S2]. The SAXS pattern was recorded for $250 \mathrm{~s}$ in order to check the reversibility of the transition after stopping the shearing experiment. Figure $\mathrm{S} 6$ shows the time relaxation of the shear induced R $\overline{3} \mathrm{~m}$ phase. 

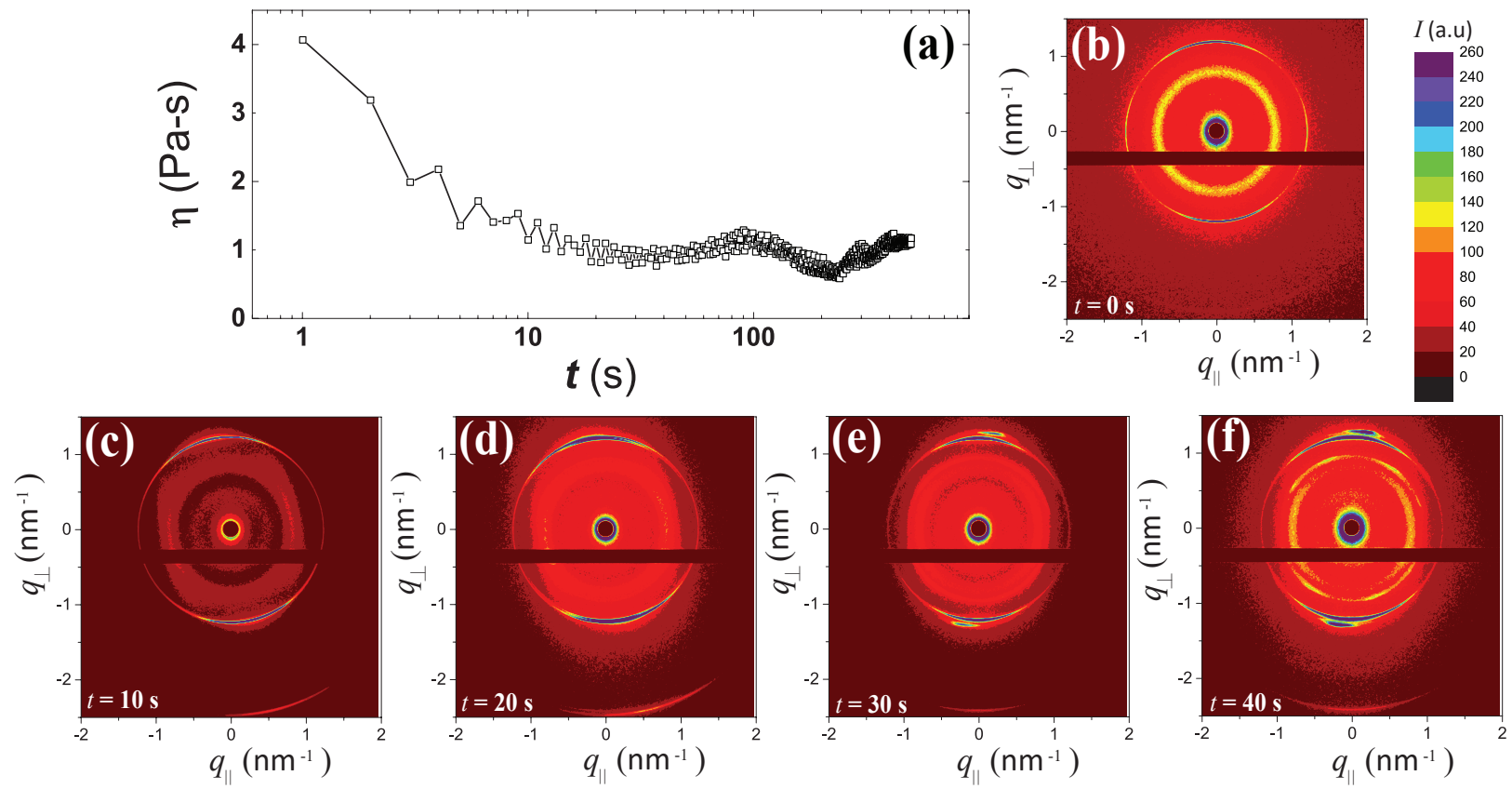

FIG. S5. With PP geometry, shear-induced NEPT from $L_{\alpha}^{D}$ phase to $\mathrm{R} \overline{3} \mathrm{~m}$ phase is observed during stress relaxation measurement with CPC-SHN-water system $(\alpha=0.5, \phi=0.55)$ at $\dot{\gamma}=50 \mathrm{~s}^{-1}$. (a) $\eta$ vs $t$ plot and the corresponding X-ray diffraction patterns at (b) $t=0 \mathrm{~s}$, (c) $t=10 \mathrm{~s}$, (d) $t=20 \mathrm{~s}$, (e) $t=30 \mathrm{~s}$, (f) $t=40 \mathrm{~s}$ are shown. The intensity color scale (shown in the right corner) is the same for all the patterns in this figure. 


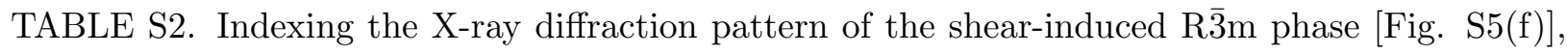
obtained by shearing the $\mathrm{L}_{\alpha}^{D}$ phase (CPC-SHN-water system, $\alpha=0.5, \phi=0.55$ ) at $\dot{\gamma}=50 \mathrm{~s}^{-1}$. Peaks are fitted to set of two R $\overline{3} \mathrm{~m}$ phases with the calculated unit cell parameters as $a 1=8.39$ $\mathrm{nm}, c 1=14.79 \mathrm{~nm}\left(1^{s t} \mathrm{R} \overline{3} \mathrm{~m}\right)$ and $a 2=8.27 \mathrm{~nm}, c 2=14.28 \mathrm{~nm}\left(2^{\text {nd }} \mathrm{R} \overline{3} \mathrm{~m}\right)$.

\begin{tabular}{|c|c|c|c|c|c|c|}
\hline & $1^{s t}$ & $\mathrm{R} \overline{3} \mathrm{~m}$ & $2^{\text {nd }}$ & $\mathrm{R} \overline{3} \mathrm{~m}$ & & \\
\hline $\begin{array}{l}d_{o b s} \\
(\mathrm{~nm})\end{array}$ & $h k l$ & $\begin{array}{r}d_{c a l} \\
(\mathrm{~nm})\end{array}$ & $h k l$ & $\begin{array}{r}d_{c a l} \\
(\mathrm{~nm})\end{array}$ & $\begin{array}{c}\text { error } \\
(\%)\end{array}$ & intensity \\
\hline 6.52 & 101 & 6.52 & & & 0 & strong \\
\hline 6.40 & & & 101 & 6.40 & 0 & strong \\
\hline 5.06 & 012 & 5.18 & 012 & 5.06 & $2.3,0$ & very strong \\
\hline 4.93 & 003 & 4.93 & & & 0 & very strong \\
\hline 4.76 & & & 003 & 4.76 & 0 & very strong \\
\hline 3.20 & 113 & 3.19 & 202 & 3.20 & $0.3,0$ & weak \\
\hline 3.10 & & & 113 & 3.12 & 0.6 & weak \\
\hline 2.53 & 006 & 2.47 & 122 & 2.53 & $2.4,0$ & weak \\
\hline
\end{tabular}




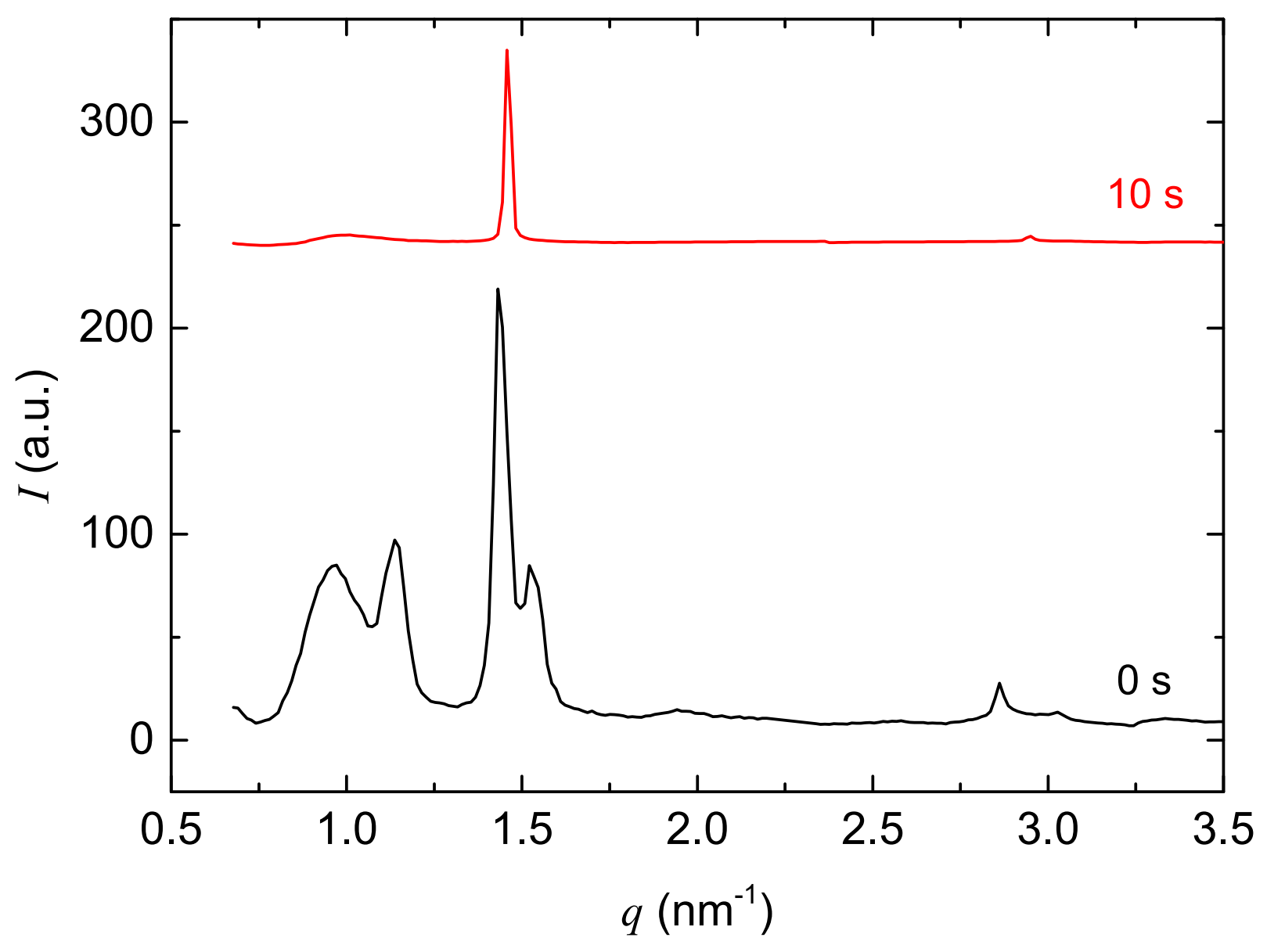

FIG. S6. Time relaxation of the shear induced rhombohedral mesh phase $(\mathrm{R} \overline{3} \mathrm{~m})$, obtained by shearing the random mesh phase $\left(\mathrm{L}_{\alpha}^{D}\right)$ at $\dot{\gamma}=50 \mathrm{~s}^{-1}$, for CPC-SHN-water $(\alpha=0.5, \phi=0.55)$. 


\section{E. Equilibrium study of the rhombohedral mesh phase using Rheo-SALS and}

Rheo-SAXS setups

Figure S7 shows the SALS and the SAXS patterns from the ordered mesh phase at equilibrium just before the rheology measurements. The equilibrium patterns are azimuthally isotropic centering the central beam spot and independent of the geometry in use, a typical signature of randomly oriented crystalline domains. The positions of the SAXS rings in $q$-space can be indexed to a rhombohedral unit cell having the space group symmetry $\mathrm{R} \overline{3} \mathrm{~m}$.
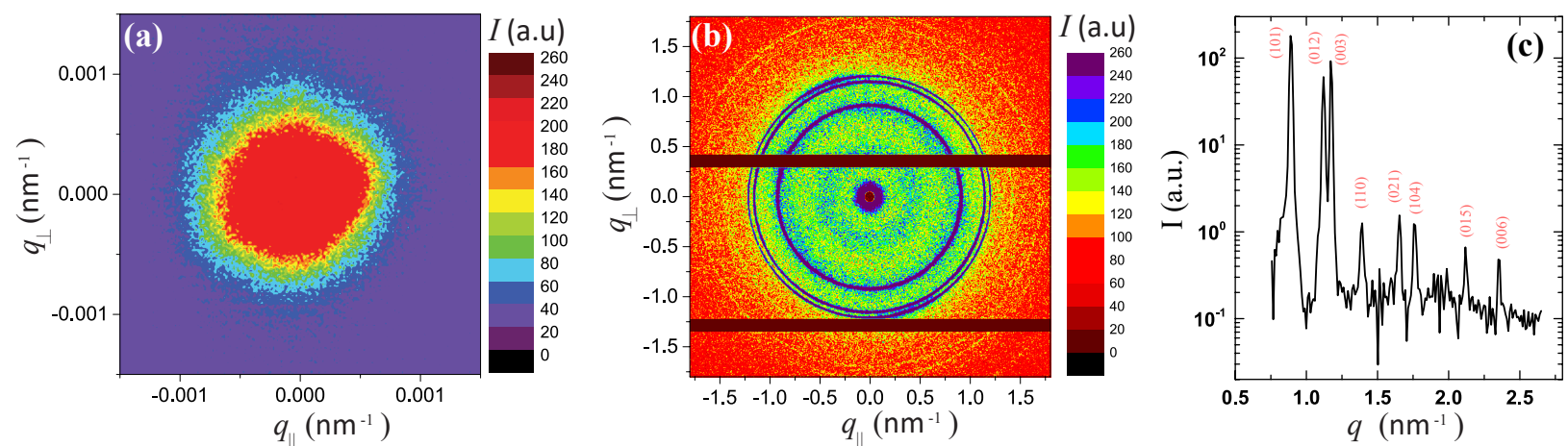

FIG. S7. Equilibrium patterns from the rhombohedral phase formed by CTAB-SHN-Water ternary system at $30^{\circ} \mathrm{C}$ : (a) Small angle light scattering (SALS) pattern (weight fraction $\phi=0.53$, and $\alpha=1$ ) and (b) small angle X-ray scattering (SAXS) pattern (weight fraction $\phi=0.65$, and $\alpha=1$ ) are shown. These patterns were captured while the samples were resting between the rheometer plates. (c) Intensity vs wave vector $(q)$ plot of the SAXS shows the positions of the isotropic rings in $q$-space. Fitted lattice panes (having $\mathrm{R} \overline{3} \mathrm{~m}$ symmetry) are indicated. The intensity color scales are shown after the respective patterns. 
F. Rheo-SALS during the shear stress controlled flow curve measurement with $\mathbf{R} \overline{3} \mathbf{m}$ phase

The rheo-SALS measurements were performed separately in PP glass geometry with VH configuration. Figure $\mathrm{S} 8$ shows the shear stress-controlled flow curve where the shear stress was varied from $100 \mathrm{~Pa}$ to $1000 \mathrm{~Pa}$ with a waiting time of $200 \mathrm{~s}$ at each point. The unaligned scattering pattern [Fig. S8(a)] transforms to a partially aligned at $\sigma=200 \mathrm{~Pa}$ [Fig. S8(b)] and then shows a-oriented bilayers, bilayer planes parallel to the velocity-velocity gradient plane at $300 P a$ [Fig. S8(c)]. Interestingly, at $600 P a$ and above, a star-like pattern appears [Fig. S8 (d)]. 

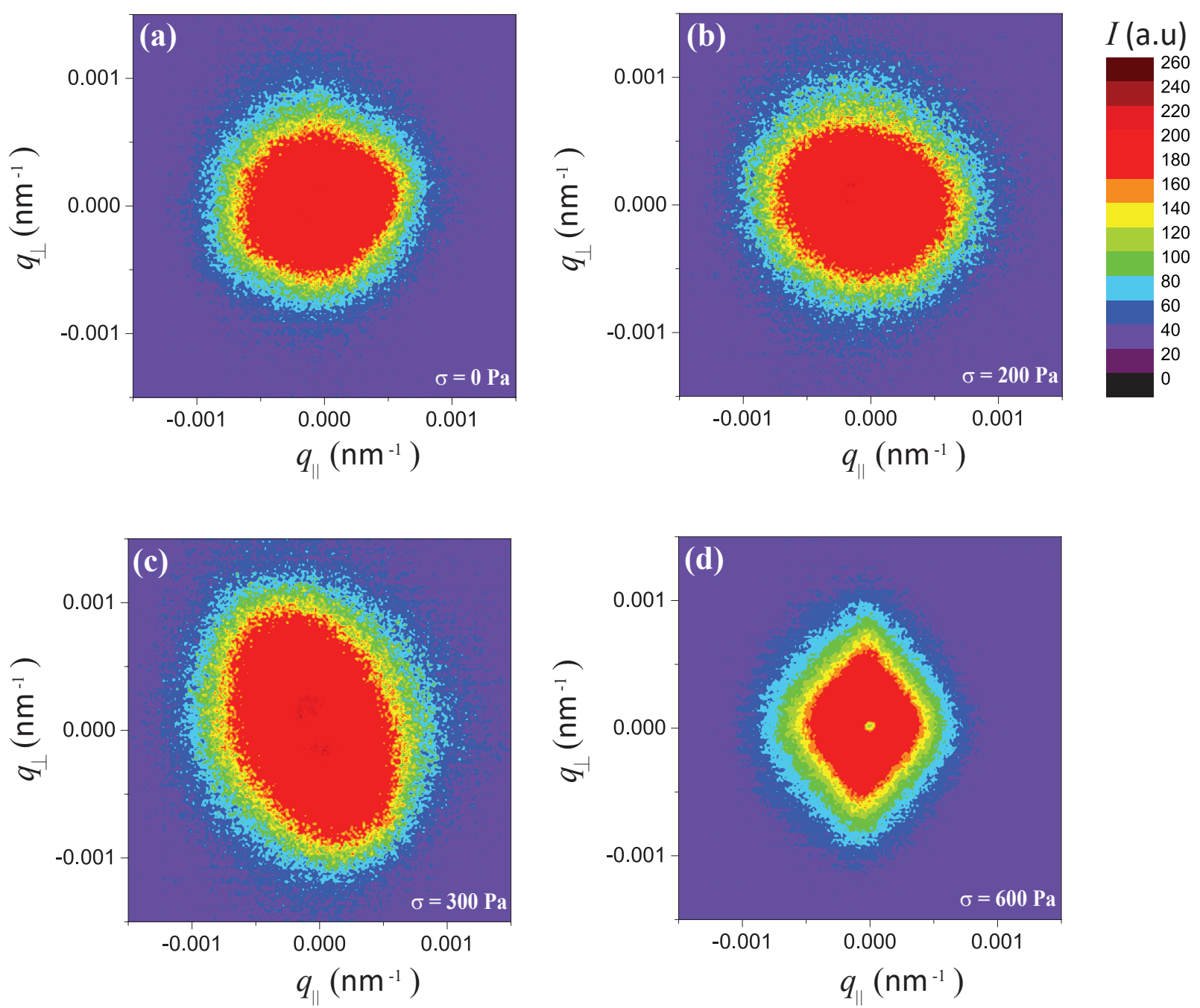

FIG. S8. SALS patterns obtained during the shear stress controlled flow curve measurement, are shown for different $\sigma$ : (a) 0Pa, (b) 200Pa, (c) 300Pa, (d) 600Pa. The intensity color scale (shown in the right corner) is the same for all the patterns in this figure. 


\section{G. The lattice parameters of $\mathrm{R} \overline{3} \mathbf{m}$ at different position in the Couette gap}

The change in the lattice parameters of the $\mathrm{R} \overline{3} \mathrm{~m}$ vs the distance of the $\mathrm{x}$-ray beam from the inner stator cylinder of the Couette geometry $\left(g_{x}\right)$ is plotted [Fig. S9], during the shear rate relaxation of $\mathrm{R} \overline{3} \mathrm{~m}$ (CTAB-SHN-water system, $\alpha=1, \phi=0.53$ ) for $\sigma=100 \mathrm{~Pa}$.

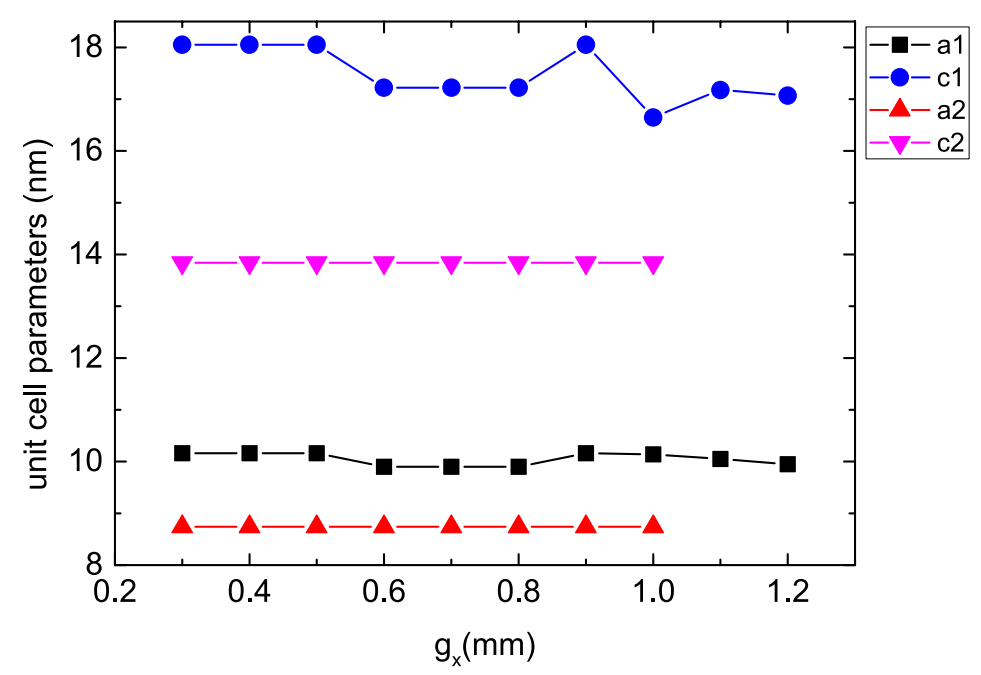

FIG. S9. Lattice parameters vs the distance of the x-ray beam from the inner stator cylinder $\left(g_{x}\right)$ during the shear rate relaxation of R $\overline{3} \mathrm{~m}$ (CTAB-SHN-water system, $\alpha=1, \phi=0.53$ ) for $\sigma=100$ Pa, done in Couette geometry. (Patterns are shown in the main text Fig. 7(b)). 
TABLE S3. Indexing the X-ray diffraction patterns shown in the main text Fig. 4, obtained by shearing the $\mathrm{L}_{\alpha}^{D}$ phase (CTAB-SHN-water system, $\left.\alpha=1, \phi=0.5\right)$ at $\dot{\gamma}=50 \mathrm{~s}^{-1}$. The average in-plane nano-pore separation $\left(d_{d}\right)$ and the lamellar $d$-spacing $\left(d_{l}\right)$ are marked. For the patterns at $t=515 \mathrm{~s}$ and at $t=850 \mathrm{~s}$ revealing the shear-induced $\mathrm{R} \overline{\mathrm{m}} \mathrm{m}$ phase, the calculated $d$-spacings $\left(d_{c a l}\right)$ are obtained using the relation $(1 / d)^{2}=(4 / 3)\left(h^{2}+h k+k^{2}\right) / a^{2}+l^{2} / c^{2}$ with the condition $-h+k+l=3 n$, where $n$ is an integer. The calculated unit cell parameters $a=8.68 \mathrm{~nm}, c=15.93$ $\mathrm{nm}$ are same for both.

\begin{tabular}{|c|c|c|c|c|c|}
\hline $\begin{array}{c}t \\
(\mathrm{~s})\end{array}$ & $\begin{array}{c}d_{o b s} \\
(\mathrm{~nm})\end{array}$ & $h k l$ & $\begin{array}{c}d_{c a l} \\
(\mathrm{~nm})\end{array}$ & $\begin{array}{c}\text { error } \\
(\%)\end{array}$ & intensity \\
\hline \multirow[t]{3}{*}{0} & $7.67\left(d_{d}\right)$ & & & 0 & broad \\
\hline & $5.49\left(d_{l}\right)$ & & & 0 & very strong \\
\hline & $2.76\left(d_{l} / 2\right)$ & & & 0.5 & strong \\
\hline \multirow[t]{3}{*}{50} & $7.92\left(d_{d}\right)$ & & & 0 & broad \\
\hline & $5.31\left(d_{l}\right)$ & & & 0 & very strong \\
\hline & $2.68\left(d_{l} / 2\right)$ & & & 0.9 & strong \\
\hline \multirow[t]{6}{*}{515} & $7.79\left(d_{d}\right)$ & & & 0 & broad \\
\hline & 6.80 & 101 & 6.80 & 0 & very strong \\
\hline & 5.49 & 012 & 5.47 & 0.4 & strong \\
\hline & $5.31\left(d_{l}\right)$ & 003 & 5.31 & 0 & very strong \\
\hline & 4.39 & 110 & 4.34 & 1.1 & weak \\
\hline & $2.68\left(d_{l} / 2\right)$ & 006 & 2.66 & 0.8 & strong \\
\hline \multirow[t]{9}{*}{850} & $7.79\left(d_{d}\right)$ & & & 0 & broad \\
\hline & 6.80 & 101 & 6.80 & 0 & very strong \\
\hline & 5.49 & 012 & 5.47 & 0.4 & very strong \\
\hline & $5.31\left(d_{l}\right)$ & 003 & 5.31 & 0 & very strong \\
\hline & 4.39 & 110 & 4.34 & 1.1 & strong \\
\hline & 3.77 & 021 & 3.66 & 2.9 & weak \\
\hline & 3.53 & 104 & 3.52 & 0.3 & strong \\
\hline & 3.02 & 015 & 2.93 & 3 & weak \\
\hline & $2.66\left(d_{l} / 2\right)$ & 006 & 2.66 & 0 & strong \\
\hline
\end{tabular}


TABLE S4. Indexing the X-ray diffraction patterns shown in the main text Fig. 5 , for different $\sigma$.

\begin{tabular}{|c|c|c|c|c|c|c|}
\hline $\begin{array}{c}\sigma \\
(\mathrm{Pa})\end{array}$ & $\begin{array}{l}d_{o b s} \\
(\mathrm{~nm})\end{array}$ & $h k l$ & $\begin{array}{c}d_{c a l} \\
(\mathrm{~nm})\end{array}$ & $\begin{array}{l}\text { error } \\
(\%)\end{array}$ & intensity & $\begin{array}{l}\text { unit cell } \\
\qquad(\mathrm{nm})\end{array}$ \\
\hline \multirow[t]{7}{*}{0} & 7.00 & 101 & 7.00 & 0 & very strong & $a=8.95$ \\
\hline & 5.65 & 012 & 5.62 & 0.5 & weak & $c=16.32$ \\
\hline & 5.44 & 003 & 5.44 & 0 & strong & \\
\hline & 4.47 & 110 & 4.47 & 0 & very strong & \\
\hline & 3.78 & 021 & 3.77 & 0.3 & strong & \\
\hline & 2.81 & 024 & 2.81 & 0 & weak & \\
\hline & 2.28 & 220 & 2.24 & 1.8 & weak & \\
\hline \multirow[t]{8}{*}{470} & 7.00 & 101 & 7.00 & 0 & very strong & $a=8.96$ \\
\hline & 5.61 & 012 & 5.60 & 0.2 & weak & $c=16.20$ \\
\hline & 5.40 & 003 & 5.40 & 0 & strong & \\
\hline & 4.47 & 110 & 4.48 & 0.2 & very strong & \\
\hline & 3.78 & 021 & 3.77 & 0.3 & strong & \\
\hline & 3.59 & 104 & 3.59 & 0 & strong & \\
\hline & 2.97 & 015 & 2.99 & 0.7 & weak & \\
\hline & 2.69 & 006 & 2.70 & 0.4 & weak & \\
\hline \multirow[t]{5}{*}{590} & 7.00 & 101 & 7.00 & 0 & very strong & $a=9.00$ \\
\hline & 5.61 & 012 & 5.57 & 0.7 & strong & $c=15.93$ \\
\hline & 5.31 & 003 & 5.31 & 0 & very strong & \\
\hline & 4.47 & 110 & 4.50 & 0.7 & strong & \\
\hline & 2.66 & 006 & 2.66 & 0 & strong & \\
\hline \multirow[t]{8}{*}{660} & 7.00 & 101 & 7.00 & 0 & very strong & $a=8.98$ \\
\hline & 5.57 & 012 & 5.59 & 0.4 & very strong & $c=16.05$ \\
\hline & 5.35 & 003 & 5.35 & 0 & very strong & \\
\hline & 4.45 & 110 & 4.49 & 0.9 & very strong & \\
\hline & 3.78 & 021 & 3.78 & 0 & weak & \\
\hline & 3.55 & 104 & 3.57 & 0.6 & strong & \\
\hline & 2.96 & 015 & 2.97 & 0.3 & weak & \\
\hline & 2.67 & 006 & 2.68 & 0.4 & very strong & \\
\hline
\end{tabular}


TABLE S5. Indexing the X-ray diffraction pattern shown in the main text Fig. 6(b) for $g_{x}=0.6$

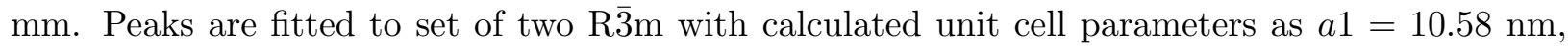
$c 1=18.60 \mathrm{~nm}\left(1^{s t} \mathrm{R} \overline{3} \mathrm{~m}\right)$ and $a 2=8.50 \mathrm{~nm}, c 2=14.25 \mathrm{~nm}\left(2^{\text {nd }} \mathrm{R} \overline{3} \mathrm{~m}\right)$.

\begin{tabular}{|c|c|c|c|c|c|c|}
\hline \multirow[b]{2}{*}{$\begin{array}{l}d_{o b s} \\
(\mathrm{~nm})\end{array}$} & \multicolumn{2}{|c|}{$1^{\text {st }} \mathrm{R} \overline{3} \mathrm{~m}$} & \multicolumn{2}{|c|}{$2^{n d} \mathrm{R} \overline{3} \mathrm{~m}$} & \multirow[b]{2}{*}{$\begin{array}{l}\text { error } \\
(\%)\end{array}$} & \multirow[b]{2}{*}{ intensity } \\
\hline & $h k l$ & $\begin{array}{c}d_{c a l} \\
(\mathrm{~nm})\end{array}$ & $h k l$ & $\begin{array}{c}d_{c a l} \\
(\mathrm{~nm})\end{array}$ & & \\
\hline 8.22 & 101 & 8.22 & & & 0 & very strong \\
\hline 6.54 & 012 & 6.53 & 101 & 6.54 & $0.2,0$ & very strong \\
\hline 6.20 & 003 & 6.20 & & & 0 & very strong \\
\hline 5.22 & 110 & 5.29 & & & 1.3 & very strong \\
\hline 5.10 & & & 012 & 5.12 & 0.4 & very strong \\
\hline 4.75 & & & 003 & 4.75 & 0 & very strong \\
\hline 2.93 & 006 & 3.10 & 113 & 3.17 & $5.5,7.6$ & strong \\
\hline
\end{tabular}


TABLE S6. Indexing the X-ray diffraction patterns observed at $g_{x}=0.8 \mathrm{~mm}$ for different $\sigma$, shown in the main text Fig. 7. For $\sigma=100 \mathrm{~Pa}$, peaks are fitted to set of two R $\overline{3} \mathrm{~m}$ phases with calculated unit cell parameters as $a 1, c 1\left(1^{\text {st }} \mathrm{R} \overline{3} \mathrm{~m}\right)$ and $a 2, c 2\left(2^{\text {nd }} \mathrm{R} \overline{3} \mathrm{~m}\right)$. Lamellar peaks are marked by $d_{l}$ and $d_{l} / 2$. Peak intensity vs, s, and w represent very strong, strong, and weak respectively.

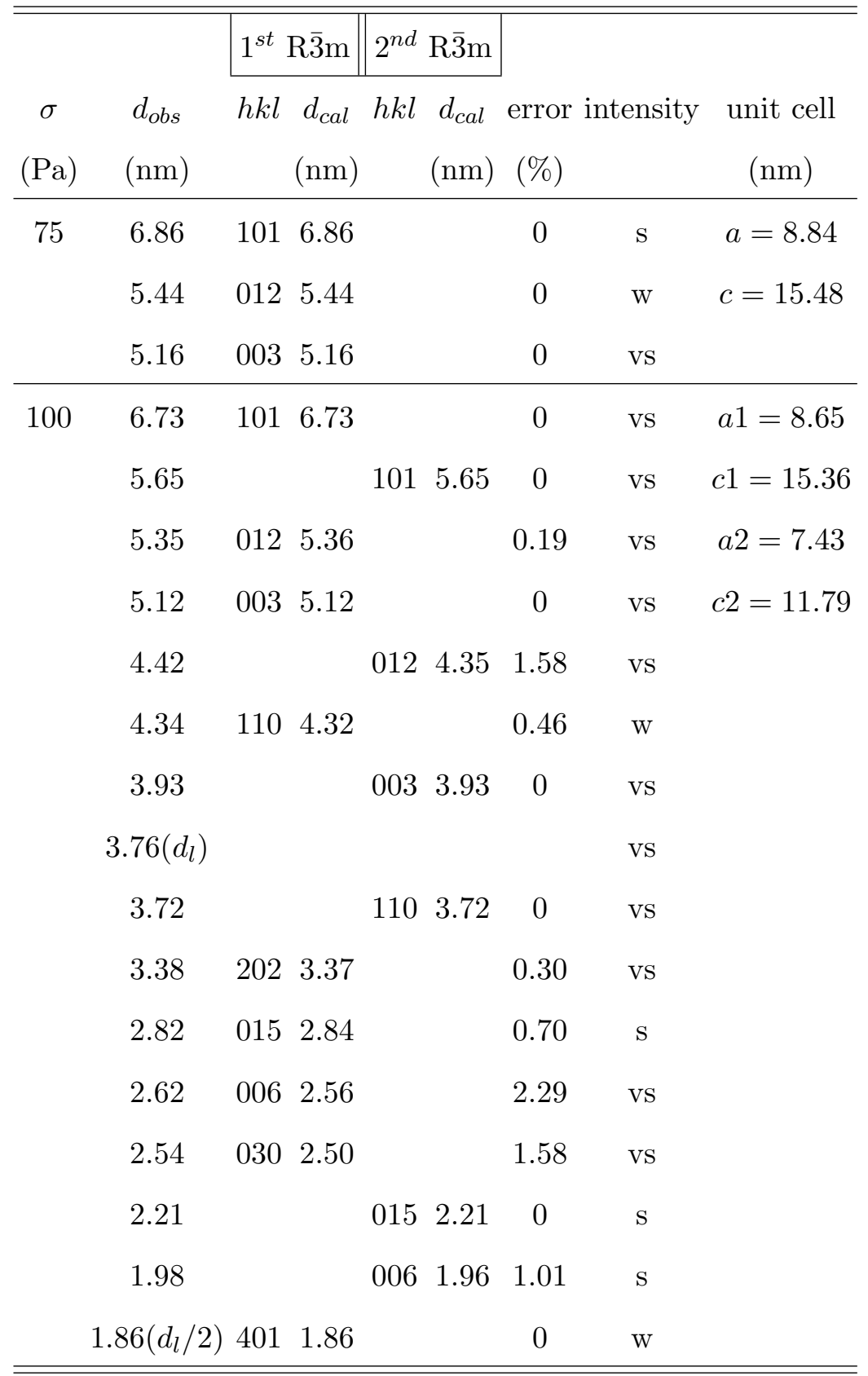


TABLE S7. Indexing the X-ray diffraction pattern shown in the main text Fig. 8(d). Peaks are fitted to set of two $\mathrm{R} \overline{3} \mathrm{~m}$ phases with calculated unit cell parameters as $a 1=8.13 \mathrm{~nm}, c 1=13.80$ $\mathrm{nm}\left(1^{\text {st }} \mathrm{R} \overline{3} \mathrm{~m}\right)$ and $a 2=7.69 \mathrm{~nm}, c 2=13.80 \mathrm{~nm}\left(2^{\text {nd }} \mathrm{R} \overline{3} \mathrm{~m}\right)$.

\begin{tabular}{|c|c|c|c|c|c|c|}
\hline & $1^{s t}$ & $\mathrm{R} \overline{3} \mathrm{~m}$ & $2^{n d}$ & $\mathrm{R} \overline{3} \mathrm{~m}$ & & \\
\hline $\begin{array}{l}d_{o b s} \\
(\mathrm{~nm})\end{array}$ & $h k l$ & $\begin{array}{c}d_{\text {cal }} \\
(\mathrm{nm})\end{array}$ & $h k l$ & $\begin{array}{c}d_{\text {cal }} \\
(\mathrm{nm})\end{array}$ & $\begin{array}{l}\text { error } \\
(\%)\end{array}$ & intensity \\
\hline 6.27 & 101 & 6.27 & & & 0 & very strong \\
\hline 6.00 & & & 101 & 6.00 & 0 & very strong \\
\hline 4.82 & & & 112 & 4.79 & 0.6 & very strong \\
\hline 4.60 & 003 & 4.60 & 003 & 4.60 & 0,0 & very strong \\
\hline 4.09 & 110 & 4.06 & & & 0.7 & weak \\
\hline 3.89 & & & 110 & 3.85 & 1.0 & weak \\
\hline 3.48 & 021 & 3.41 & & & 2.0 & strong \\
\hline 3.26 & & & 021 & 3.24 & 0.6 & strong \\
\hline 3.08 & & & 104 & 3.06 & 0.6 & strong \\
\hline 2.30 & 006 & 2.30 & & & 0 & strong \\
\hline
\end{tabular}


TABLE S8. Indexing the X-ray diffraction pattern shown in the main text Fig. 9(f). Peaks are fitted to set of two $\mathrm{R} \overline{3} \mathrm{~m}$ phases with calculated unit cell parameters as $a 1=7.76 \mathrm{~nm}, c 1=13.80$ $\mathrm{nm}\left(1^{s t} \mathrm{R} \overline{3} \mathrm{~m}\right)$ and $a 2=7.38 \mathrm{~nm}, c 2=13.17 \mathrm{~nm}\left(2^{n d} \mathrm{R} \overline{3} \mathrm{~m}\right)$.

\begin{tabular}{|c|c|c|c|c|c|c|}
\hline \multirow[b]{2}{*}{$\begin{array}{c}d_{o b s} \\
(\mathrm{~nm})\end{array}$} & \multicolumn{2}{|c|}{$1^{s t} \mathrm{R} \overline{3} \mathrm{~m}$} & \multicolumn{2}{|c|}{$2^{\text {nd }} \mathrm{R} \overline{3} \mathrm{~m}$} & \multirow[b]{2}{*}{$\begin{array}{c}\text { error } \\
(\%)\end{array}$} & \multirow[b]{2}{*}{ intensity } \\
\hline & $h k l$ & $\begin{array}{r}d_{c a l} \\
(\mathrm{~nm})\end{array}$ & $h k l$ & $\begin{array}{c}d_{c a l} \\
(\mathrm{~nm})\end{array}$ & & \\
\hline 6.04 & 101 & 6.04 & & & 0 & very strong \\
\hline 5.75 & & & 101 & 5.75 & 0 & very strong \\
\hline 4.83 & 012 & 4.81 & & & $0.4,0$ & very strong \\
\hline 4.60 & 003 & 4.60 & 012 & 4.59 & $0,0.22$ & very strong \\
\hline 4.39 & & & 003 & 4.39 & 0 & very strong \\
\hline 3.08 & 104 & 3.07 & 021 & 3.11 & $0.32,0.97$ & weak \\
\hline 2.29 & 006 & 2.30 & 024 & 2.29 & $0.43,0$ & strong \\
\hline
\end{tabular}




\section{REFERENCES}

[1] R. Krishnaswamy, S. K. Ghosh, S. Lakshmanan, V. A. Raghunathan, and A. K. Sood, Langmuir 21, 10439 (2005).

[2] S. P. Gupta and V. A. Raghunathan, Physical Review E 88, 012503 (2013). 